\title{
Expression of miRNA-146a in nasopharyngeal carcinoma is upregulated by Epstein-Barr virus latent membrane protein 1
}

\author{
YINGHAI ZHAO $^{1}$, XIAOYI CHEN ${ }^{1}$, MIN JING $^{2}$, HAIJUN DU $^{3}$ and YI ZENG $^{3}$ \\ ${ }^{1}$ Department of Pathology, Guangdong Medical College, Zhanjiang 524023; \\ ${ }^{2}$ Department of Pathology, the First People's Hospital of Nei Jiang, Neijiang 641000; ${ }^{3}$ National Institute \\ for Viral Disease Control and Prevention, Chinese Center for Disease Prevention and Control, State \\ Key Laboratory for Infectious Disease Prevention and Control, Beijing 100052, P.R. China
}

Received April 12, 2012; Accepted May 24, 2012

DOI: $10.3892 /$ or.2012.1933

\begin{abstract}
We aimed to investigate the relationship between miRNA-146a and latent membrane protein 1 (LMP1) of Epstein-Barr virus (EBV) in nasopharyngeal carcinoma (NPC). The expression levels of LMP1 in 40 cases of NPC, 28 cases of chronic nasopharyngitis and NPC cell lines CNE1 and CNE1-GL (in which LMP1 was stably transfected) were detected by immunohistochemical staining. The expression of miRNA-146a in 16 cases of NPC, 13 cases of chronic nasopharyngitis and cell lines was determined by quantitative reverse transcription polymerase chain reaction (qRT-PCR) analysis. A plasmid containing the luciferase gene under the control of miRNA-146a promoter (pri-miRNA-146a) was constructed and transfected into NPC cells, and the luciferase activity was detected. LMP1 was positive in $17.9 \%(5 / 28)$ of chronic nasopharyngitis cases and $62.5 \%$ (25/40) of NPC cases $(\mathrm{P}<0.01)$. The miRNA-146a levels in NPC were significantly higher than that in chronic nasopharyngitis $(\mathrm{P}<0.01)$, and were higher in CNE1-GL cells than those in CNE1 cells $(\mathrm{p}<0.01)$. The expression of miRNA-146a in human NPC was elevated by EBV-associated antigen LMP1, probably through the activation of the miRNA-146a promoter.
\end{abstract}

\section{Introduction}

Nasopharyngeal carcinoma (NPC) is a malignant cancer of epithelial cell origin. It has a high incidence in Southeast Asia and Southern China and is closely associated with infection by Epstein-Barr virus (EBV) (1-5). According to the different antigens generated during infection, latent EBV infections in human can be classified into latency type I, II and III infections. During latency I infection, only a small number of gene

Correspondence to: Dr Xiaoyi Chen, Department of Pathology, Guangdong Medical College, Zhanjiang 524023, P.R. China E-mail: 18924333954@189.cn

Key words: miRNA-146a, Epstein-Barr virus, nasopharyngeal carcinoma, latent membrane protein 1 products are produced [EBV-encoded small RNAs (EBERs) and EBV nuclear antigen 1 (EBNA1)]. In type II latent infection, the infected host cell will produce EBERs, EBNA1, latent membrane protein 1 (LMP1), LMP2A, LMP2B and other transcripts. In type III latent infection, EBNAs, EBERs and LMPs are also seen. Latent EBV infection in NPC is usually of type II $(1,4)$.

LMP1 is one of the latent EBV infection-associated antigens, which is closely related with the carcinogenic effects of EBV. As an oncoprotein, LMP1 can cross-link by using its C-terminal cytoplasmic domain and analog $\mathrm{CD}_{40}$ to mediate intracellular signalling pathways. LMP1 can activate transcription factor activator protein 1 (AP-1) and nuclear factor kappa-light-chain-enhancer of activated B cells $(\mathrm{NF}-\kappa \mathrm{B})$ signal transduction through its binding to the tumor necrosis factor receptor-associated death domain protein (TRADD) or to the tumor necrosis factor receptor-associated factor (TRAF). Therefore, LMP1 plays a key role in cell proliferation, apoptosis, cell transformation, invasion and metastasis via regulating the expression of downstream target genes (6-8). Most of NPC biopsies are positive for LMP1 expression $(3,9)$.

EBV can integrate into the host cell genome at chromosomal fragile sites which are often prone to sister chromatid exchanges, chromosomal translocations, gene deletions, gene amplifications and oncogenic virus integrations. EBV can integrate into human chromosomes at 1p, 1q, 2q, 3p, 3q, 4q, 5q, $6 q, 7 p, 7 q, 9 q, 11 p, 14 q$ and $15 q(10,11)$. EBV infection also can cause a loss of heterozygosity $(\mathrm{LOH})$ at chromosome 5q11-q14 and 5q31-q33 loci (10).

microRNAs (miRNAs) are endogenous, 19-25-nucleotide long, single-stranded small non-coding RNA transcripts. They interact with the $3^{\prime}$ UTR of target mRNA, resulting in inhibition of translation of the target gene or target degradation. It has been found that the expression levels and patterns of miRNAs in human cancer cells and tissues show significant difference from those of normal cells and tissues (12). Human miRNAs have been found frequently (52\%) at fragile sites in the cancerassociated genomic regions or genes, including $\mathrm{LOH}$ region, genomic breakpoints and fragile sites where genetic abnormality often occurs in the cancer cells (13). Functionally, some miRNAs are similar to oncogenes or tumor suppressor genes 
and post-transcriptionally regulate the expression of cancerrelated genes (14-17).

Human miRNA-146a is located within the second exon of 5q33.3 LOC285628 gene which has two exons and an intermediate intron of approximate size of $16 \mathrm{~kb}(18,19)$. Overexpression of miRNA-146a has been observed in various malignant tumors, such as papillary thyroid carcinoma, pediatric acute leukemia and hepatocellular carcinoma (20-25). LMP1 can also increase the expression of miR-146a in malignant lymphoma $(21,22)$.

Recent studies have shown that miRNA encoded by oncogenic viruses or by the human genome may play an important regulatory role in virus-host interactions (26-29). Clarifying the mechanism of action of miRNAs not only helps to understand the virus-host interaction but also helps to decipher the development of virus-induced tumors. Our present study aims to explore the relationship between miRNA-146a expression and EBV-associated antigen LMP1 in the context of NPC and its possible mechanism.

\section{Materials and methods}

Specimens and cell lines. Specimens of non-keratinizing undifferentiated nasopharyngeal carcinoma, and chronic nasopharyngitis were obtained from the diagnosed outpatients at the Affiliated Hospital of Guangdong Medical College. Informed consent was provided by all patients. All NPC patients had not been treated with radiotherapy or chemotherapy.

Of the 40 cases of NPC patients whose specimens were used for immunohistochemical detection, 12 cases were at TNM stage I, 12 cases were at stage II, 10 cases were at stage III and 6 cases were at stage IV. Twenty-seven were males and 13 were females, with age ranging from 30 to 75 years, median age of 46 years and mean age of 46.5 years. Of the 28 cases of chronic nasopharyngitis patients, 17 were males and 11 were females, with age ranging from 17 to 80 years, median age of 40 years and mean age of 40.6 years. Of the 16 NPC patients ( 5 cases of TNM stage I, 4 cases of stage II, 4 cases of stage III and 3 cases of stage IV) whose specimens were detected by qRT-PCR, 11 were male and 5 were females, with age ranging from 28 to 78 years, median age of 46 years and mean age of 46.6 years. Of the 13 patients with chronic nasopharyngitis, 7 were males and 6 were females, with age ranging from 24 to 73 years, median age of 44 years and mean age of 44.1 years.

Nasopharyngeal carcinoma cell line CNE1 and CNE1-GL were from the Department of Pathology, Guangdong Medical College. CNE1-GL was transfected with a eukaryotic expression plasmid pAT-GFP-LMP containing LMP1 gene and green fluorescent protein (GFP) as reporter gene, which was a gift from Dr J.R. Arrand from the Paterson Institute for Cancer Research, Christie CRC Research Center, Manchester, UK (30).

Immunohistochemical staining. Slides of paraffin-embedded specimens and cells were incubated overnight with mouse anti-human LMP1 monoclonal antibody (Dako) (1:100) in a humidified box at $4^{\circ} \mathrm{C}$, washed thrice with PBS, incubated with streptavidin-peroxidase (SP) for $1 \mathrm{~h}$ at room temperature, washed for three times and stained by diaminobenzidine (DAB). Sections with known high LMP1 expression were used as positive controls and sections incubated with PBS instead of primary antibody served as negative controls.

For each section, 5 low magnification fields (x100) were randomly selected under the microscope, and the proportions of positively stained cells per field was counted under higher magnification (x400). The results are presented as the mean percentage of the 5 fields. The rating criteria were as follows: no positive cells in the field was ranked as 0 ; positive cells $\leq 10 \%$ as $1 ; 11-50 \%$ as $2 ; 51-75 \%$ as $3 ;>75 \%$ as 4 . The criteria for staining intensity was: no staining was ranked as 0 ; light yellow staining as 1; brown staining as 2 ; dark brown staining as 3. The LMP1 staining was evaluated according to the number of positive cells and staining intensity. The sections with a number of positive cells of 0 were recognized as negative (-), while sections with a number $\geq 1$ were positive $(+)$. The results of all the sections were subjected to review by three pathologists who were blinded to the study design.

Quantitative reverse transcription polymerase chain reaction ( $q R T-P C R)$. The total RNAs of NPC tissues and chronic nasopharyngitis tissues were extracted with TRIzol reagent (Invitrogen, Carlsbad, CA, USA) and were reversely transcribed into complementary DNA (cDNA) using miScript Reverse Transcription kit (Qiagen, Germany). The cDNAs were diluted 1:10, 1:100 and 1:1000 and then amplified by miScript SYBR-Green PCR kit (Qiagen) in the Applied Biosystems 7300 Real-time PCR System (Applied Biosystems, Foster City, CA, USA). The primers for miRNA-146a and reference gene were as follows: upstream primer of miRNA146a 5'-TGAGAACTGAATTCCATGGGTT-3', downstream primer 5'-ATCTACTCTCTCCAGGTCCTCA-3' and upstream primer for the reference gene U6 small nuclear RNA (snRNA) 5'-CTCGCTTCGGCAGCACA-3', downstream primer 5'-AA CGCTTCACGAATTTGCGT-3'. The relative changes in the expression of miRNA-146a were calculated in accordance with $2^{-\Delta \Delta C t}$ method (31).

Construction of pGL3-miR146a-pri-pro plasmid. Primers for the miRNA-146a promoter were synthesized as previously described (22): upstream primer 5'-GCAGCTAGCTTTCGG TCCATGAGCACGT-3' (NheI restriction site is underlined); downstream primer 5'-GCA $\underline{\text { AAGCTTAGCGGTCAAGCGT }}$ CTTGG-3' (HindIII restriction site is underlined). The sequence from -1153 to +21 of miRNA-146a gene promoter was amplified by PCR. The PCR products were purified, digested with NheI and HindIII and ligated with the expression vector pGL3-Basic containing firefly (Photinus pyralis) luciferase gene (Promega, Madison, WI, USA) with the aid of T4 DNA ligase. After transformation, positive clones were screened by restriction enzyme digestion. The correct construct was verified by DNA sequencing and named as pGL3-miR146apri-pro.

Transfection and detection of luciferase activity. CNE1 or CNE1-GL cells $\left(2 \times 10^{4}\right)$ were seeded into 24 -well plates and incubated in a humidified $5 \% \mathrm{CO}_{2}$ incubator at $37^{\circ} \mathrm{C}$ for $24 \mathrm{~h}$. When the cells reached $60-70 \%$ confluence, $1 \mu \mathrm{g}$ of pGL3-Basic or pGL3-miR146a-pri-pro with $10 \mathrm{ng}$ pRL-TK, a plasmid containing Renilla luciferase reporter gene and $100 \mathrm{ng}$ pRL-SV40 plasmid were co-transfected 

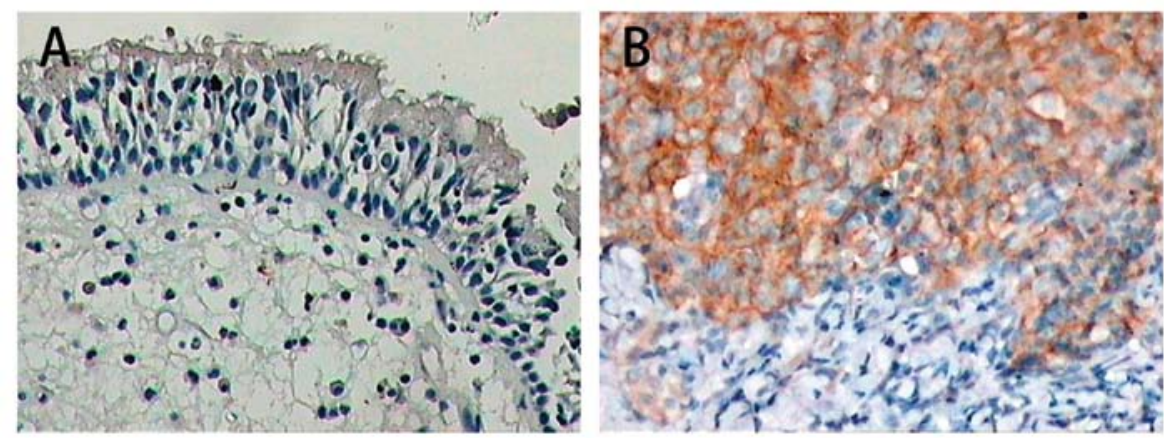

Figure 1. LMP1 expression in chronic nasopharyngitis and NPC specimens. (A) No expression of LMP1 protein in chronic nasopharyngitis (SP, $\mathrm{x} 400$ ). (B) Positive staining of LMP1 protein in NPC (SP, x400).
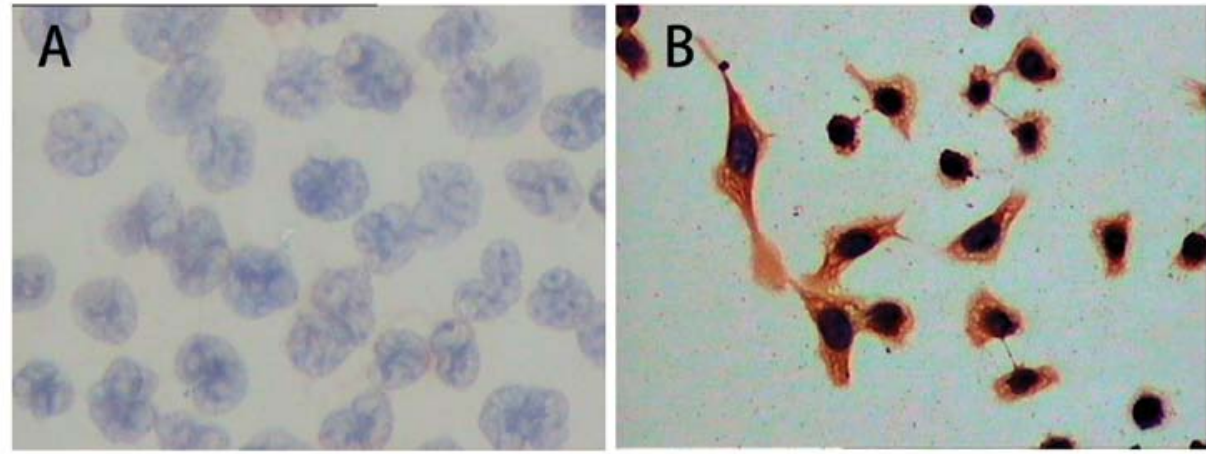

Figure 2. Expression of LMP1 in NPC cell lines. (A) No expression of LMP1 protein in CNE1 cells (SP, x400). (B) Positive staining of LMP1 protein in CNE1-GL cells (SP, x200).

Table I. Expression of LMP1 in NPC and chronic nasopharyngitis specimens.

\begin{tabular}{lcccc}
\hline Conditions & $\mathrm{n}$ & Positive & Negative & Positive (\%) \\
\hline Chronic nasopharyngitis & 28 & 5 & 23 & 17.9 \\
NPC & 40 & 25 & 15 & $62.5^{\mathrm{a}}$ \\
\hline
\end{tabular}

${ }^{\mathrm{a} P}=0.002 ; \chi^{2}=13.315$.

using Lipofectamine 2000 (Invitrogen, Carlsbad, CA, USA). After $48 \mathrm{~h}$, the firefly and Renilla luciferase enzyme assays were conducted by using the dual luciferase reporter assay system (Promega) and fluorescence intensity was detected by GloMax $^{\circledR} 96$ Microplate Luminometer (Promega) in the transfected cells. The expression of firefly luciferase was calculated using the formula $\Delta \mathrm{CT}=(\mathrm{F} / \mathrm{R})_{\text {sample }} /(\mathrm{F} / \mathrm{R})_{\text {control }}$, where $\mathrm{F}$ refers to the intensity of firefly luciferase and $\mathrm{R}$ is the intensity of Renilla luciferase. Each treatment was performed in triplicate.

Statistical analysis. Data are presented as means \pm standard deviation (SD). Statistical comparisons for percentages were performed using $\chi^{2}$ analysis in each case. For continuous variables, Mann-Whitney U test was used. All statistical analyses were carried out by using SPSS 13.0 (SPSS Inc., Chicago, IL, USA). P-values $<0.05$ were considered statistically significant (2-tailed).

\section{Results}

Different expression of LMPI in chronic nasopharyngitis, NPC specimens and NPC cell lines. LMP1 expression in NPC and chronic nasopharyngitis specimens was detected by immunohistochemical staining. It was observed that LMP1 protein was located on the cell membrane (Fig. 1). LMP1 expression was found in 5 out of 28 (17.9\%) cases of chronic nasopharyngitis, while the percentage of positive staining of LMP1 was $62.5 \%(25 / 40)$ in the NPC specimens. The difference of LMP1 expression between the two groups was statistically significant $(\mathrm{P}<0.01)$ (Table I).

The results of immunocytochemical staining showed that LMP1 protein was abundantly expressed and distributed in the cell membrane and cytoplasm of CNE1-GL cells. However, expression of LMP1 protein was not detected in CNE1 cells (Fig. 2 and Table II). 
Table II. Expression of LMP1 in different NPC cell lines.

\begin{tabular}{lcc}
\hline & \multicolumn{2}{c}{ LMP1 } \\
\cline { 2 - 3 } Cell lines & Positive (n) & Positive (\%) \\
\hline CNE1 & 0 & 0 \\
CNE1-GL & $492 \pm 11$ & $98.4 \pm 2.2$ \\
\hline
\end{tabular}

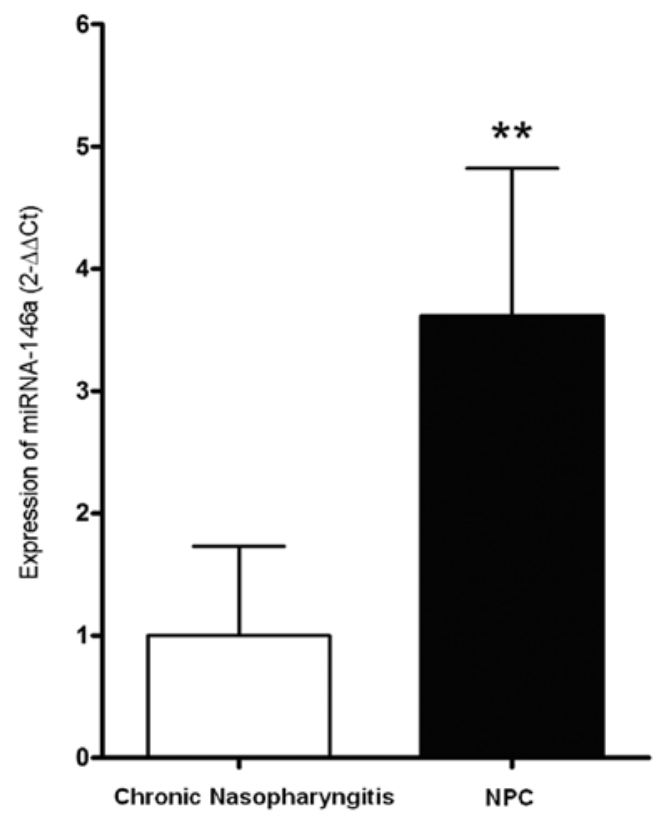

Figure 3. The expression of miRNA-146a in NPC and chronic nasopharyngitis. Data are presented as mean $\pm \mathrm{SD},{ }^{* *} \mathrm{P}<0.01$.

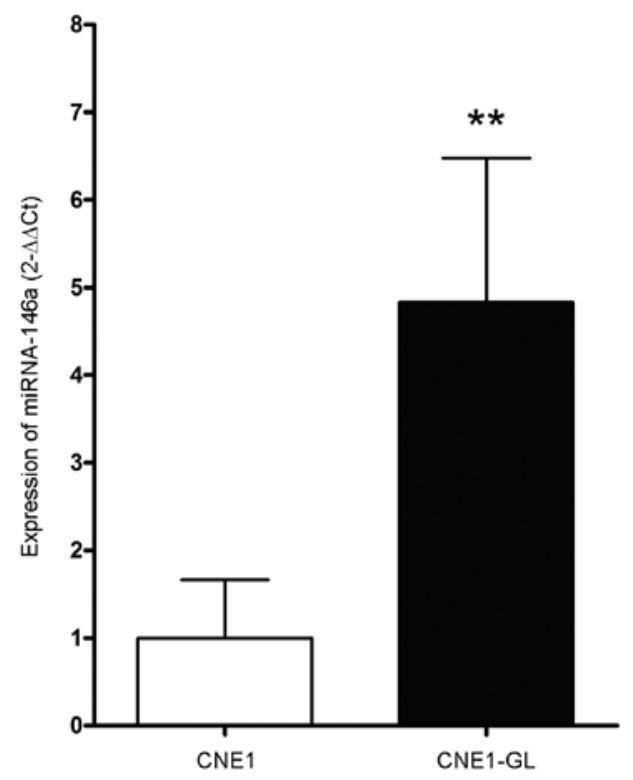

Figure 4. The expression of miRNA-146a in CNE1-GL cells and CNE1 cells. Data are presented as mean $\pm \mathrm{SD},{ }^{* *} \mathrm{P}<0.01$.

Expression of miRNA-146a in chronic nasopharyngitis, NPC specimens and NPC cell lines. The result of qRT-PCR
A $\quad$ CNE-1
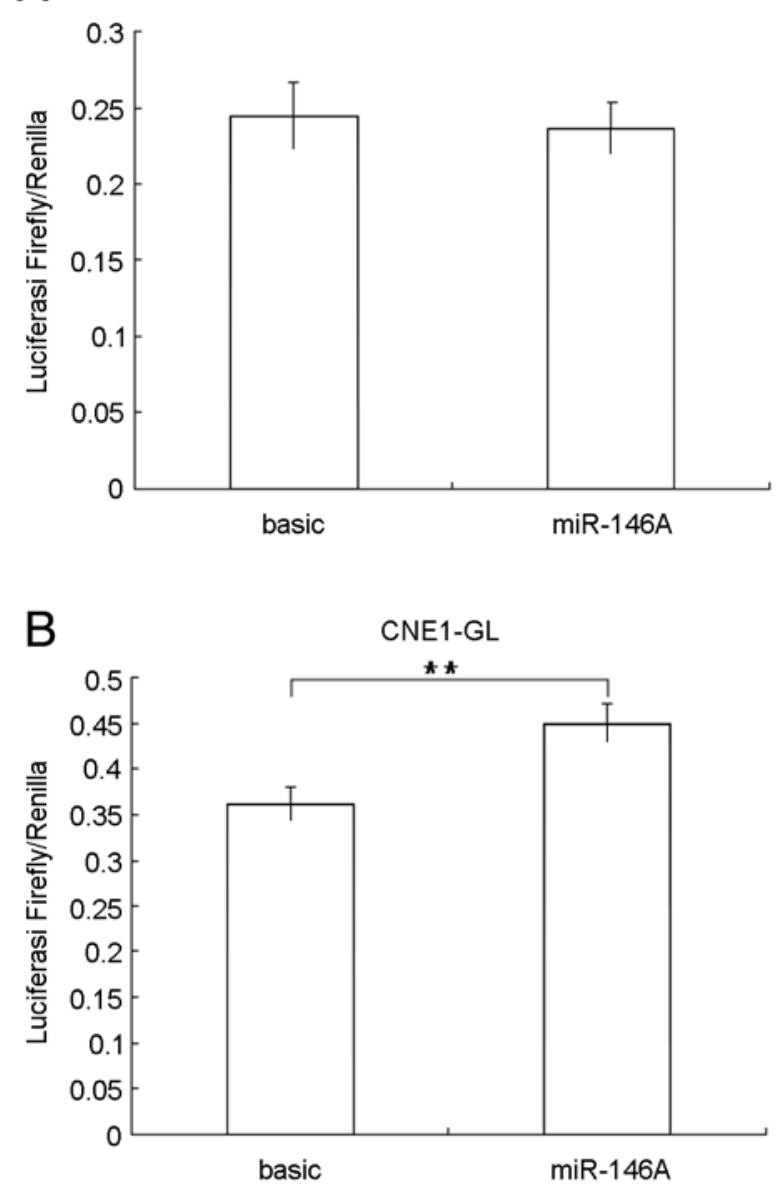

Figure 5. The expression of pri-miRNA-146a in NPC cell lines after transfection with recombinant plasmids. (A) CNE1 cell line, (B) CNE1-GL cell line.

revealed that the expression level of miRNA-146a in NPC was $3.62 \pm 1.20$ times higher than that in chronic nasopharyngitis $(\mathrm{P}<0.01)$ (Fig. 3).

Similarly, as shown in Fig. 4, the miRNA-146a level in CNE1-GL cells was $4.83 \pm 1.64$ times higher than that in CNE-1 cells $(\mathrm{P}<0.01)$.

The relationship between LMP1 and miRNA-146a. To explore the relationship between LMP1 and miRNA-146a, we constructed the plasmid pGL3-miR146a-pri-pro to transfect NPC cells (CNE1 and CNE1-GL) with different LMP1 status. It was shown that $\triangle \mathrm{CT}$ values of $\mathrm{CNE} 1$ cells transfected with pGL3-Basic or the recombinant plasmid pGL3-miR146a-pripro did not make significant difference $(\mathrm{P}=0.207)$ (Fig. 5A). The expression level of firefly luciferase in pGL3-miR146apri-pro transfected CNE1 cells was 0.967 that of pGL3-Basic transfected cells, suggesting that the activity of miR146a promoter was not effective in CNE1 cells.

In contrast, the $\triangle \mathrm{CT}$ value of CNE1-GL cells transfected with plasmid pGL3-miR146a-pri-pro was significantly higher than that of CNE1-GL cells transfected with pGL3-Basic $(\mathrm{P}=0.0042)$ (Fig. 5B). The expression level of firefly luciferase in CNE1-GL cells was 1.240 higher than that of pGL3-Basic transfected cells, suggesting that activity of miR146a promoter may be upregulated by LMP1. 


\section{Discussion}

In the present study, we found that the miRNA-146a expression level in 16 cases of human non-keratinizing undifferentiated NPC was significantly elevated $(\mathrm{P}<0.01)$, compared to that in 13 cases of chronic nasopharyngitis, indicating that the higher expression of miRNA-146a could be a potential indicator for NPC development. EBV infection is an important stimulus for oncogenesis of NPC (1-5), and EBV is detectable in almost all of the non-keratinizing undifferentiated nasopharyngeal carcinoma. The latent EBV infection involved in NPC is type II $(1,4)$. In general, in the state of latent infection EBV genome persists in the host cell as an episome, but sometimes the EBV genome also integrates into the chromosomes of the host cell (32). Many integration sites in human chromosomes have been confirmed, such as 1p, 1q, 2q, 3p, 3q, 4q, 5q, 6q, 7p, $7 \mathrm{q}, 9 \mathrm{q}, 11 \mathrm{p}, 14 \mathrm{q}$ and 15q $(10,11)$. miRNA-146a is in the second exon of LOC285628 gene which is located coincidentally, on chromosome 5q33.3 $(18,19)$. This suggests that the increased expression of miRNA-146a may be the result of the enhanced promoter activity of miRNA-146a, due to integration of the EBV genome.

On the other hand, LMP1 as an EBV latent infectionassociated antigen that can mimic $\mathrm{CD}_{40}$-mediated signal transduction pathways, which participate in regulation of cell proliferation, apoptosis, malignant transformation, invasion and metastasis. To further determine whether the elevated expression level of miRNA-146a in human NPC is directly related to LMP1, we used immunohistochemical/immunocytochemical methods to detect LMP1 protein expression in paraffin-embedded sections of the NPC cell lines with/ without stably transfected LMP1 gene. The expression of miRNA-146a was quantified by qRT-PCR in parallel. The results showed that in both the specimens and cell lines, the expression levels of miRNA-146a were positively correlated with that of LMP1 protein expression. It was confirmed that the LMP1 can upregulate the expression level of miRNA146a. To investigate the mechanism involved in regulation of miRNA-146a by LMP1, we constructed a dual luciferase reporter gene vector pGL3-mir146a-pri-pro which was transfected into CNE1 and CNE1-GL cells, using pGL3Basic as a control. The results showed that when compared to CNE1 cells (no LMP1 expression), the pri-miRNA-146a level in CNE1-GL cells (LMP1 expressing) was significantly upregulated. The dual luciferase reporter assay indicated that in NPC cells LMP1 protein significantly enhanced the expression of miRNA-146a via promoter activation. As one of the main regulators of EB virus, LMP1 can simulate the CD40 receptor and activate multiple cell signaling pathways

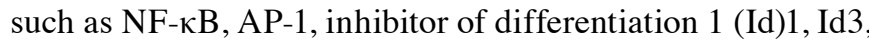
signal transducers and activators of transcription (STAT) and TNF receptor-associated factors (TRAFs), thus enlarging the downstream regulation of target gene expression. $\mathrm{CD}_{40}$ activates cells by a signaling pathway that begins with the association of adapter proteins known as TRAFs. TRAFs are thought to interact with $\mathrm{CD}_{40}$ to nuclear factor $(\mathrm{NF})-\kappa \mathrm{B}$ and c-Jun kinase (JNK) activation. Similar to $\mathrm{CD}_{40}$, LMP1 also binds TRAFs which are then thought to interact with kinases such as $\mathrm{NF}-\kappa \mathrm{B}$-inducing kinase that ultimately promote activation of $\mathrm{NF}-\kappa \mathrm{B}(33-38)$. However, further investigation on the exact interaction between LMP1 and miRNA-146a is still needed.

In conclusion, this study confirmed that miR-146a expression was correlated with the expression of EBV-associated antigen LMP1 in NPC in vitro and in vivo. LMP1 may elevate the expression of miRNA-146a via promoter activation, which adds new evidence to EBV-host interactions.

\section{Acknowledgements}

This study is supported by the National Basic Research Program of China (973 Program), 2011CB504800.

\section{References}

1. Brooks L, Yao QY, Rickinson AB and Young LS: Epstein-Barr virus latent gene transcription in nasopharyngeal carcinoma cells: coexpression of EBNA1, LMP1, and LMP2 transcripts. J Virol 66: 2689-2697, 1992.

2. Thompson MP and Kurzrock R: Epstein-Barr virus and cancer. Clin Cancer Res 10: 803-821, 2004.

3. Zhang M, Zong YS, He JH, Lin SX, Zhong BL and Liang YJ: Comparison of Epstein-Barr virus infection and 30 bp-deleted LMP1 gene among four histological types of nasopharyngeal carcinoma. Chin Med J 117: 608-611, 2004.

4. Tao Q, Young LS, Woodman CB and Murray PG: EpsteinBarr virus (EBV) and its associated human cancers - genetics, epigenetics, pathobiology and novel therapeutics. Front Biosci 11: 2672-2713, 2006

5. Zheng H, Li LL, Hu DS, Deng XY and Cao Y: Role of Epstein-Barr virus encoded latent membrane protein 1 in the carcinogenesis of nasopharyngeal carcinoma. Cell Mol Immunol 4: 185-196, 2007.

6. Akiba $\mathrm{H}$, Nakano H, Nishinaka $\mathrm{S}$, et al: $\mathrm{CD} 27$, a member of the tumor necrosis factor receptor superfamily, activates NF-kappaB and stress-activated protein kinase/c-Jun N-terminal kinase via TRAF2, TRAF5, and NF-kappaB-inducing kinase. J Biol Chem 273: 13353-13358, 1998 .

7. Deng L, Yang J, Zhao XR, et al: Cells in G2/M phase increased in human nasopharyngeal carcinoma cell line by EBV-LMP1 through activation of NF-kappaB and AP-1. Cell Res 13: 187-194, 2003.

8. Thornburg NJ, Kulwichit W, Edwards RH, Shair KH, Bendt KM and Raab-Traub N: LMP1 signaling and activation of NF-kappaB in LMP1 transgenic mice. Oncogene 25: 288-297, 2006.

9. Young LS and Rickinson AB: Epstein-Barr virus: 40 years on. Nat Rev Cancer 4: 757-768, 2004.

10. Shao JY, Huang XM, Yu XJ, et al: Loss of heterozygosity and its correlation with clinical outcome and Epstein-Barr virus infection in nasopharyngeal carcinoma. Anticancer Res 21: 3021-3029, 2001

11. Gao J, Luo X, Tang K, Li X and Li G: Epstein-Barr virus integrates frequently into chromosome $4 \mathrm{q}, 2 \mathrm{q}, 1 \mathrm{q}$ and $7 \mathrm{q}$ of Burkitt's lymphoma cell line (Raji). J Virol Methods 136: 193-199, 2006.

12. Bandres E, Cubedo E, Agirre X, et al: Identification by Real-time PCR of 13 mature microRNAs differentially expressed in colorectal cancer and non-tumoral tissues. Mol Cancer 5: 29, 2006.

13. Calin GA, Sevignani C, Dumitru CD, et al: Human microRNA genes are frequently located at fragile sites and genomic regions involved in cancers. Proc Natl Acad Sci USA 101: 2999-3004, 2004.

14. Chen CZ: MicroRNAs as oncogenes and tumor suppressors. $\mathrm{N}$ Engl J Med 353: 1768-1771, 2005.

15. Zhang B, Pan X, Cobb GP and Anderson TA: microRNAs as oncogenes and tumor suppressors. Dev Biol 302: 1-12, 2007.

16. Wang X, Tang S, Le SY, et al: Aberrant expression of oncogenic and tumor-suppressive microRNAs in cervical cancer is required for cancer cell growth. PLoS One 3: e2557, 2008.

17. Hurst DR, Edmonds MD, Scott GK, Benz CC, Vaidya KS and Welch DR: Breast cancer metastasis suppressor 1 up-regulates miR-146, which suppresses breast cancer metastasis. Cancer Res 69: $1279-1283,2009$. 
18. Taganov KD, Boldin MP, Chang KJ and Baltimore D: NF-kappaB-dependent induction of microRNA miR-146, an inhibitor targeted to signaling proteins of innate immune responses. Proc Natl Acad Sci USA 103: 12481-12486, 2006.

19. Luo X, Yang W, Ye DQ, et al: A functional variant in microRNA146a promoter modulates its expression and confers disease risk for systemic lupus erythematosus. PLoS Genet 7: e1002128, 2011 .

20. He H, Jazdzewski K, Li W, et al: The role of microRNA genes in papillary thyroid carcinoma. Proc Natl Acad Sci USA 102: 19075-19080, 2005.

21. Motsch N, Pfuhl T, Mrazek J, Barth S and Grasser FA: EpsteinBarr virus-encoded latent membrane protein 1 (LMP1) induces the expression of the cellular microRNA miR-146a. RNA Biol 4: 131-137, 2007.

22. Cameron JE, Yin Q, Fewell C, et al: Epstein-Barr virus latent membrane protein 1 induces cellular MicroRNA miR-146a, a modulator of lymphocyte signaling pathways. J Virol 82 : 1946-1958, 2008.

23. Jazdzewski K, Murray EL, Franssila K, Jarzab B, Schoenberg DR and de la Chapelle A: Common SNP in pre-miR-146a decreases mature miR expression and predisposes to papillary thyroid carcinoma. Proc Natl Acad Sci USA 105: 7269-7274, 2008.

24. Xu T, Zhu Y, Wei QK, et al: A functional polymorphism in the miR-146a gene is associated with the risk for hepatocellular carcinoma. Carcinogenesis 29: 2126-2131, 2008.

25. Zhang H, Luo XQ, Zhang P, et al: MicroRNA patterns associated with clinical prognostic parameters and CNS relapse prediction in pediatric acute leukemia. PLoS One 4: e7826, 2009.

26. Couturier JP and Root-Bernstein RS: HIV may produce inhibitory microRNAs (miRNAs) that block production of CD28, CD4 and some interleukins. J Theor Biol 235: 169-184, 2005.

27. Sullivan CS, Grundhoff AT, Tevethia S, Pipas JM and Ganem D: SV40-encoded microRNAs regulate viral gene expression and reduce susceptibility to cytotoxic T cells. Nature 435 : 682-686, 2005.

28. Gupta A, Gartner JJ, Sethupathy P, Hatzigeorgiou AG and Fraser NW: Anti-apoptotic function of a microRNA encoded by the HSV-1 latency-associated transcript. Nature 442: 82-85, 2006.
29. Rana TM: Illuminating the silence: understanding the structure and function of small RNAs. Nat Rev Mol Cell Biol 8: 23-36, 2007.

30. Chen Y and Chen XY: Effect of Epstein-Barr virus latent membrane protein 1 (LMP1) on apoptosis of nasopharyngeal carcinoma cell line CNE1. Ai Zheng 21: 498-503, 2002 (In Chinese).

31. Livak KJ and Schmittgen TD: Analysis of relative gene expression data using real-time quantitative PCR and the 2(-Delta Delta C(T)) method. Methods 25: 402-408, 2001.

32. Henderson A, Ripley S, Heller M and Kieff E: Chromosome site for Epstein-Barr virus DNA in a Burkitt tumor cell line and in lymphocytes growth-transformed in vitro. Proc Natl Acad Sci USA 80: 1987-1991, 1983.

33. Kieser A, Kilger E, Gires O, Ueffing M, Kolch W and Hammerschmidt W: Epstein-Barr virus latent membrane protein-1 triggers AP-1 activity via the c-Jun N-terminal kinase cascade. EMBO J 16: 6478-6485, 1997.

34. Gires O, Kohlhuber F, Kilger E, et al: Latent membrane protein 1 of Epstein-Barr virus interacts with JAK3 and activates STAT proteins. EMBO J 18: 3064-3073, 1999.

35. Everly DN Jr, Mainou BA and Raab-Traub N: Induction of Id1 and Id 3 by latent membrane protein 1 of Epstein-Barr virus and regulation of p27/Kip and cyclin-dependent kinase 2 in rodent fibroblast transformation. J Virol 78: 13470-13478, 2004.

36. Li HM, Zhuang ZH, Wang Q, et al: Epstein-Barr virus latent membrane protein 1 (LMP1) upregulates Id1 expression in nasopharyngeal epithelial cells. Oncogene 23: 4488-4494, 2004.

37. Hau PM, Tsang CM, Yip YL, Huen MS and Tsao SW: Id1 interacts and stabilizes the Epstein-Barr virus latent membrane protein 1 (LMP1) in nasopharyngeal epithelial cells. PLoS One 6: e21176, 2011

38. Talaty P, Emery A and Everly DN Jr: Characterization of the latent membrane protein 1 signaling complex of Epstein-Barr virus in the membrane of mammalian cells with bimolecular fluorescence complementation. Virol J 8: 414, 2011. 